Bulletin UASVM Food Science and Technology 70(1)/2013, 66-67

ISSN-L 2344-2344; Print ISSN 2344-2344; Electronic ISSN 2344-5300

\title{
A Comparison between Physicochemical Characteristics of the Degraded Palm Oil by Chicken Nuggets Coated with Sweet Pepper and Hot Pepper
}

\author{
Dan-Ştefan CLONDA, Nicoleta G. HĂDĂRUGĂ, Adrian RIVIŞ \\ Department of Food Science, Banat's University of Agricultural Sciences and Veterinary Medicine of \\ Timişoara, 300645-Timişoara, Calea Aradului 119, Romania \\ anaclonda@yahoo.com
}

\begin{abstract}
Palm oil was selected from varieties of vegetable oils used in the food industry (especially in the food industry of "Fast Food") and proved to be an oil with properties that can be maintained within acceptable limits for a number of uses after a reasonable time highly dependent on the type of food processed. It is known that frying is the most widely used process for the preparation of food both in the home and in industrial scale. The preference for this method of preparation of the food is due to the fact that it is a quick and convenient method from the point of view of time / output, and the food unique sensory properties, color, texture, consistency, taste and flavor are very popular with consumers. Degraded samples of the oils were analysed to ascertain the physicochemical caracteristics (density, refractive index, acid and saponification values and percentage of water) in comparison to the blank samples. The determinations conducted revealed elevated parameters due to the degradation compounds found in the analysed samples.
\end{abstract}

Keywords: palm oil, degradation, chicken nuggets, sweet/hot pepper

Introduction. The palm oil is known for its high bioavailability and excellent oxidative properties. Chicken nuggets are one of the most consumed foodstuffs in Europe, especially in the fast food restaurants. The quality of these nuggets is related to the vegetable oil used for frying, in this case palm oil. The browning reactions between carbohydrates and the proteins, the absorption of frying oil, density of the fried product, temperature and frying time intervals lead to a change of color during the frying.

Aims. The aim of this study was to obseve and evaluate the modification of the physico-chemical properties of the palm oil used for obtaining chicken nuggets coated with sweet pepper and hot pepper.

Materials and methods: The palm oil used for the experiments was bought from a local supermarket in Timisoara, Romania. The oil that was used for the analysis was obtained by dry fractionation. Chicken nuggets from Romania were bought from the supermarket and were kept at refrigerated temperature. The sweet pepper and hot pepper bags, wich are also from Romania were purchased at the local supermarket.

Samples were deep fat fried at $160^{\circ} \mathrm{C}$ for 6 minutes in commercial bench-top deep fat fryer (Moulinex) containing $2 \mathrm{~L}$ of palm oil. After each frying batch, a quantity of oil was cooled and added into a bag for futher experiments. Twenty-eight oil samples were collected and analyzed for the main physicochemical parameters. Fourteen of the samples were with the palm oil resulted from the frying of chicken nuggets with sweet pepper and the other fourteen with hot pepper. The samples were stored in a refrigirator at $5{ }^{\circ} \mathrm{C}$, for the duration of the experiments.

Results: The main physicochemical parameters vary with the degradation time of the palm oil by chicken nuggets. Thus, relative density of the palm oil used for frying chicken nuggets coated with sweet pepper increases from 0.905 for the starting material to 0.909 after 
84 minutes of degradation at $160^{\circ} \mathrm{C}$. The same variation was observed in the case of refractive index (1.4672-1.4685) and for acid (1.12-1.84 $\mathrm{mg} \mathrm{KOH} / \mathrm{g}$ ) and saponification values (150$244 \mathrm{mg} \mathrm{KOH} / \mathrm{g}$ ). No significant variation during the degradation of the palm oil was observed for the Karl Fischer water content $(0.05-0.1 \%)$. As for the palm oil from the chicken nuggets coated with hot peppers, determinations varry a little. The relative density increases from the blank at 0.905 to 0.91 after 84 minutes of degradation at $160^{\circ} \mathrm{C}$. Refractive index varies from 1.4671 to 1.4686 , acid index $1.12-1.64 \mathrm{mg} \mathrm{KOH} / \mathrm{g}$, and saponification values are from 150,44 to $224 \mathrm{mg} \mathrm{KOH} / \mathrm{g}$. Again, for the water content was no significant difference $0.05-0.09 \%$.

Conclusion: The degradation of the palm oil by chicken nuggets is clearly demonstrated by the main physicochemical parameters, which increase, due the presence of the more polar degradation compounds in the oil.

\section{REFERENCES}

1. Clonda Dan Stefan, Corpas Laura, Abraham Tiberiu, Hadaruga Nicoleta Gabriela, Physicochemical characteristics of the experimentally degraded palm oil by French fries, Current Opinion in Biotechnology, 2013, 24(1), S92

2. Clonda Dan-Stefan, Corpas Laura, Abraham Tiberiu, Hadaruga Nicoleta, Rivis Adrian, Determination of Fatty Acids with GC-MS and Evaluation of the Major Psysico-Chemical Parameters of Palm Oil, Tomori Pal Foiskola, Tudomanyos Mozaik, 9.kotet, Masodik resz, 2012, pag 137-144

3. Haizam, Azmil, Tarmizi, Ahmad, Niranjan, Keshavan, Gordon, Michael, Physico-chemical changes occurring in oil when atmospheric frying is combined with post-frying vacuum application, Food Chemistry, 2013, 136, 902-908

4. Teh Sue-Siang, Birch John, Physicochemical and quality characteristics of cold-pressed hemp, flax and canola seed oils, Journal of Food Composition and Analysis 2013, 30, 26-31

5. Qing Zhang, Cheng Liu, Zhijian Sun, Xiaosong Hu, Qun Shen, Jihong Wu, Authentication of edible vegetable oils adulterated with used frying oil by Fourier Transform Infrared Spectroscopy, Food Chemistry, 2012, 132, 1607-161 